\title{
Philosophical Theory-Construction and the Self-Image of Philosophy
}

\author{
Niels Skovgaard Olsen \\ Department of Philosophy, University of Konstanz, Konstanz, Germany \\ Email: Niels.Olsen@uni-Konstanz.de
}

Received 25 May 2014; revised 28 June 2014; accepted 10 July 2014

Copyright (C) 2014 by author and Scientific Research Publishing Inc.

This work is licensed under the Creative Commons Attribution International License (CC BY). http://creativecommons.org/licenses/by/4.0/

c) (i) Open Access

\begin{abstract}
This article takes its point of departure in a criticism of the views on meta-philosophy of P.M.S. Hacker for being too dismissive of the possibility of philosophical theory-construction. But its real aim is to put forward an explanatory hypothesis for the lack of a body of established truths and universal research programs in philosophy along with the outline of a positive account of what philosophical theories are and of how to assess them. A corollary of the present account is that it allows us to account for the objective dimension of philosophical discourse without taking recourse to the problematic idea of there being worldly facts that function as truth-makers for philosophical claims.
\end{abstract}

\section{Keywords}

Meta-Philosophy, Hacker, Williamson, Philosophical Theories

\section{Introduction}

The aim of this article is to use a critical discussion of the self-image of philosophy presented by P. M. S. Hacker as a platform for presenting an alternative, which offers an account of how to think about the purpose and character of philosophical theories. This account will be illustrated in section four by means of a list of candidates for the criteria of adequacy that philosophical theories of perception and language must be capable of fulfilling.

Williamson (2007) argues that it is time for a renewal of the self-image of analytic philosophy, because the one inherited from the linguistic turn is inadequate, if we compare it with how analytic philosophy has actually been practiced for the last 40 years. Some of the things that have happened during this period is a bloom of naturalism, a revival of metaphysics of the kind, which was earlier banned by authorities such as Kant and Wittgenstein $^{1}$, and a growing cognitive neuroscience, which claims finally to be able to solve many of the problems

${ }^{1}$ See Williamson (2007: p. 19). 
that philosophers have been grappling with for the past two millennia ${ }^{2}$. It is no wonder that issues like the compatibility of traditional armchair methodologies with naturalism, their role in metaphysical investigations, and their relation to the natural sciences are now being taken up again for discussion. Some of the other major contributions to this genre include Jackson (1998), Glock (2008), Braddon-Mitchell \& Nola (2009), Dummett (2010), and the writings of Hacker.

I here focus on Hacker's reaction to this predicament, because it is in many ways the most reactionary one. We thus find Hacker (2009a, 2009b) rejecting the revival of metaphysics and insisting on a sharp demarcation between the a priori character of philosophy and the a posteriori character of the empirical sciences, where the only real communication between the two consists in attempts of clearing up the conceptual confusions of the latter such as in Hacker \& Bennett (2003).

One of Williamson's (2007: chap 1) complaints about the linguistic turn is that it involves the mistake of reducing the subject matter of philosophy to the use of words/concepts, instead of making it the nature of the things referred to by them ${ }^{3}$. But according to Williamson, this fits very poorly with the renewed metaphysical interest in what fundamental kinds of things there are as well as with many other trends in contemporary analytic philosophy.

Hacker's response to Williamson has been very dismissive, and we will just focus on the small part of it, which is of immediate relevance for present concerns. Hacker (2006, 2009a, 2009b) attacks this assault on the linguistic turn as a misunderstanding on the grounds that none of the major contributors to the early analytic philosophy saw an opposition between being interested in the use of the concept $\mathrm{W}$ and being interested in the nature of $\mathrm{W}$.

Hacker's historical account of the development of analytic philosophy is clearly superior to that of Williamson. But this doesn't mean that Williamson's accusation is completely groundless in Hacker's own case, as we shall see. But first we need to have a look at the justification that Hacker offers for why philosophy isn't a cognitive discipline.

\section{Learning the Right Lesson from the History of Philosophy}

Hacker (2009b) takes his point of departure with the familiar observations that after more than two millennia of discussion — and plenty of attempts of securing a distinctive subject matter and method for philosophy — we are still left without a general agreed body of philosophical truths. The lesson he draws is that we must start realizing that philosophy is not fit as a cognitive discipline devoted to extending human knowledge.

His alternative suggestion is that we should start realizing that the proper role of philosophy is to deepen our understanding by pointing out conceptual truths grounded in the use of technical and non-technical concepts, which are obvious when pointed out. This undertaking then contributes to: 1) gaining a better understanding of the conceptual connections among important concepts, 2) solving/dissolving philosophical problems, and 3) clearing up conceptual confusions.

But to deny that philosophy is a cognitive discipline must imply that it is not the job of philosophers to construct theories (such as theories of perception, theories of action, theories of intentionality, theories of rationality, theories of consciousness, theories of personal identity, theories of freedom, theories of meaning, theories of knowledge, theories of normativity, theories of truth, and meta-ethical theories etc., etc.). And in fact this is a consequence that Hacker happily endorses ${ }^{4}$. Consequently, he is committed to holding that the vast number of philosophers, who have been, and continue to be, engaged in this enterprise are making a mistake; either because the theories they try to construct ought to be considered the province of the empirical sciences, or because they try to theorize about matters, which one only thinks that one can construct a philosophical theory about, if one is guilty of serious conceptual confusions.

I think that the dramatic changes of the philosophical practice that this would lead to are too high a price to pay. This should probably make us pause and investigate whether there are any other viable alternatives. In response, I will therefore offer a different explanatory hypothesis of the familiar observations we began with along with an account of how to think about philosophical theories in theoretical philosophy.

\footnotetext{
${ }^{2}$ See Hacker \& Bennett (2003: pp. 396-399) for some representative quotes. However, this important issue of the impact on philosophy by the growing cognitive neuroscience is not one Williamson addresses.

${ }^{3}$ Actually Williamson distinguishes between the linguistic turn and the conceptual turn, but this distinction is of minor importance for present purposes.

${ }^{4}$ See Hacker \& Bennett (2003: p. 401).
} 
Before we go on, we must get one thing straight: the problem is not that there is no progress at all in philosophy ${ }^{5}$. Rather the problem is that the kind of progress we do find in philosophy is very dissimilar to the kind we find in the accumulative natural sciences, which have an extensive body of established truths and are able to gather around widely shared research programs. For clearly there is a lot of progress in philosophy in regard to: 1) getting a better overview of the landscape of theoretical possibilities, 2) identifying the strengths and weaknesses of different ways of developing these possibilities into systematic accounts, and 3) in terms of learning which explanatory challenges such accounts must be capable of meeting.

This leaves a graveyard of rejected possibilities, where the attempts to develop them into systematic accounts turned out to be inconsistent, unstable, rest on conflations or dubious assumptions, have implausible consequences, demonstrate a failure to meet central explanatory challenges etc., etc.. Some of the perhaps most uncontroversial examples are: subjective idealism, substance dualism, logical behaviorism, phenomenalism, the sense-data theory, radical epistemological foundationalism, the stereotypical pragmatic theory of truth (which holds that truth is what works), the philosophy of science of logical positivism, strong versions of social constructivism, the verification theory of meaning, theories of meaning that identify meaning with private images, and Platonist theories of meaning (which rely on odd metaphysical entities and non-standard cognitive faculties).

However, this kind of progress is a negative one in the sense that it primarily has to do with the identification of failures. That is, what we learn from it is in the first instance how to identify inadequate ways of systematically thinking about the topics in question. But that philosophers are good at burying their own ideas is, of course, not the same as that they are getting any closer at answering a list of perennial questions, or that philosophy generates new insights on its own. And if this were the only kind of progress philosophy could produce, then it would be a bit disappointing 6 .

However, in addition to this, philosophers have also made a range of particular discoveries. Here the list may be more controversial, but candidates include: the principle of contradiction, intensional contexts, the compositionality of language, the problems posed by vagueness, that there are contexts with de re/de dicto ambiguities, intentional inexistence (i.e. that intentional relations are different from non-intentional worldly relations in that they can persist, although one of the relata doesn't exist), the normativity of intentionality ${ }^{7}$, that there are three distinct uses of "is" involved in predication, existential claims, and identity claims, that there can be no such thing as a private language, that proper names are rigid designators ${ }^{8}$, that there are counterexamples to the standard definition of knowledge as justified true beliefs, that the immediate non-conceptual Given cannot play a justifying role, and that the quick refutation of relativism as being self-refuting doesn't work as neatly as philosophers like to think ${ }^{9}$.

In fact, Gutting (2009) is able to show through a series of excellent case studies that philosophers have more knowledge at their disposal than is commonly recognized in terms of knowledge of useful conceptual distinctions, which arguments are cogent, and of how best to combine various theoretical commitments. Nevertheless, progress such as this doesn't give philosophy a body of established truths comparable to the one found in the natural sciences. It still seems that wherever one looks, there is a never-ending battle-zone of disagreeing philosophers. This brings us back to the familiar observations that we started out with.

In response, I will undertake the task of articulating a role for theory-construction in philosophy, which allows us to come to terms with the fact that it is very much unlike the one we find in the accumulative natural sciences, so that we can start focusing on some of the benefits of doing philosophy in the way it has always been done. This contrasts sharply with both the reaction of Williamson (2007), who sees the lack of a body of established truths and universal research programs as a failure to be overcome, and with the one of Hacker (2009b), who sees it as a wake-up call that philosophy shouldn't be engaged in theory-construction to begin with.

The type of explanation that Williamson (2007) seeks of the familiar observations we started out with is accordingly that the problem is merely that the approach/method has been wrong all along. It is first now that we

\footnotetext{
${ }^{5}$ On this first part, Hacker (2009b) seems to agree, even if our characterizations of this progress differ in the details.

${ }^{6}$ Moreover, as Davidson (1996) argues, the track record in arriving at non-circular definitions of the central concepts in terms of necessary and sufficient conditions is not looking much better.

${ }^{7}$ See Brandom (2001).

${ }^{8}$ Gutting (2009: pp. 85-86) argues that this thesis has become generally accepted in spite of whatever other differences there may be between contemporary theories of reference.

${ }^{9}$ See Nozick (2001: chap. 1).
} 
have achieved the sophistication required to put an end to the beginning (292) —where the relevant kind of progress is the advance in logics initiating with Frege (45). Hacker (2009a) argues that this is a matter of wishful thinking. Too many great philosophers have proclaimed that now is the end of the beginning, and too few philosophical problems have actually been solved by logical means alone, for it to have any credibility, he argues.

Given the activities of places like the Munich Center of Mathematical Philosophy, and the publication of books like Spohn (2012), it is not obvious that he is right in this last part of his assessment. And it is at any rate not something that should merely be asserted in the absence of careful argumentation. On the other hand, I am also hesitant about expecting a future, where everything is different, and where philosophy will finally be able to mimic the development of the natural sciences. The discipline has already been around long enough for us to have a good estimate of what it is capable of accomplishing and of how it should proceed.

Of course, we can all, always try to do better. But I think that we have plenty of examples of excellent philosophy in the way it is currently being practiced as it is. So instead of regretting the current state of play either by treating all those, who advance theories and make substantial metaphysical claims, as being guilty of a serious mistake, or expecting that the true potential of the discipline will first be revealed in some distant future, I suggest we consider the possibility that the discipline as we know it is essentially what philosophy is like. This involves not being blinded by the expectation that if philosophy is to be engaged in theory-construction, then its merits have to be evaluated on its capacity to produce a body of established philosophical truths comparable to the one found in the natural sciences. To show what other merits philosophical theory-construction could possibly have, I will now illustrate my suggestions by two examples.

\subsection{Two Brief Case Studies}

Had the only purpose of philosophical theory-construction been to play the midwife of the sciences, which makes itself superfluous by developing theories in new areas until a point, where they can finally be handed over to empirical testing, then it might be argued that the race is now over for philosophical theories of meaning.

As Williamson (2007: p. 281ff) points out, truth-conditional semantics has already become a flourishing branch of empirical linguistics, so why keep researching into alternative theories of meaning like assertibility theories? This may seem pointless; especially if one sees the previous lack of a body of established philosophical truths as a failure to be overcome. And the situation doesn't look much better, if Williamson is right that no systematic alternatives to truth-conditional semantics have been produced from the assertibilist camp.

But here Williamson actually leaves out at least one systematically developed alternative, which tries to preserve the close connection between meaning and use of assertibility theories without sacrificing the attitudetranscendent notion of semantic objectivity of semantic realism; to wit, the theory advanced by Brandom in Making it Explicit.

The idea here is not to choose sides, but rather to use this controversy to make a general point about the merits of philosophical theory-construction. For why write a 700 pages tome on inferentialism, if it is already clear that truth-conditional semantics has established itself as part of a successful empirical research program ${ }^{10}$ ? If philosophy continues in this way, then it is no wonder that it never reaches consensus, and perhaps it should therefore be lamented. However, as Williamson (2007: p. 283) notices, there is an ongoing debate about whether proponents of truth-conditional semantics, and an epistemically unconstrained notion of truth, are capable of giving a non-circular account of what linguistic competence consists in so as to connect the latter with practical abilities of competent speakers. Hence, this gives us at least one remaining explanatory challenge, which semantic realists must be capable of meeting, and until this has happened, the door is open for attempts of developing systematic alternatives and challenging the present authorities.

Now it may very well be that inferentialism is full of flaws and that this challenge can be met by further developments of truth-conditional semantics. So much the better, because then we at least learned this much from the resulting discussion. Perhaps more insights of this kind can be learned, if we continue to compare this theory with alternatives, instead of just closing off the discussion, because one thinks that it is time to move on. Indeed, publications such as Brandom (1994/1998) and Peacocke (2010) show that there is still much creative potential in this seemingly "barren" debate.

Of course, by continuing to question the basic assumptions of even successful theories, and developing sys-

\footnotetext{
${ }^{10}$ Incidentally, Chomsky (2000) has a different perception of how well-established truth-conditional semantics in its typical conjunction with externalist theories of reference really is in linguistics.
} 
tematic alternatives, philosophers may never agree on universal research programs. But instead they succeed in generating new ideas and investigating the weaknesses and strengths of different theoretical possibilities for the sake of finding out what illumination they can provide for the central, theoretical challenges. If the present theories can stand the pressure of being tested in this way by being systematically contrasted with alternatives in a critical discussion, it is only to be expected that they come out stronger. And if they can't, it must be considered, whether they don't belong in the graveyard of rejected possibilities after all ${ }^{11}$. This leaves room for philosophy as an independent discipline, which is not constrained to one particular subject matter, but which takes up deep theoretical questions wherever they arise and submits theories to a systematic testing of the abovementioned kind.

Another example that in some ways parallels the present one is this. Functionalism in the philosophy of mind greatly influenced the phase of cognitive science known as cognitivism. However, this didn't stop the theoretical discussion from continuing systematically to hold it up against alternative theories of mind, and rightly so. Now we are seeing some of the fruit from this ongoing discussion in the fact that phenomenological theories of mind are currently inspiring another phase in the development of cognitive science known by its proponents as embodied cognitive science ${ }^{12}$. But we would have seen none of this, if we had followed the advice of those attracted to the view that the job of philosophy is merely to make itself superfluous by developing ideas to a level of systematicity, where they can be handed over to the empirical sciences. Proponents of such a view must have thought that philosophy of mind made itself dispensable already back in the sixties, when functionalism became part of an empirical research program. And perhaps they would advise us to stop developing alternative theories of mind now with the arrival of embodied cognitive science. But I suggest that this would be a bit premature, insofar as it is still unknown what future creative inputs the ongoing philosophical debate is capable of generating.

These examples are instructive, because they suggest that an obvious reason why philosophers are so bad at reaching consensus may be that they have an overproduction of alternative theories, and that philosophy is far more critical of the basic assumptions than the stereotypical image of other disciplines that we are holding it up against ${ }^{13}$. But this is not necessarily so terrible, because no one can dispute that philosophy has had, and continues to have $\mathrm{e}^{14}$, an enormous impact on other disciplines. We just need to understand this influence in the right way.

\subsection{The Alternative}

On the picture I am presenting, philosophy should keep challenging basic theoretical assumptions, subjecting theories to rigorous theoretical criticism, and developing systematic alternatives, which try to combine theoretical commitments and meet explanatory challenges in new ways. I thus consider it as central to the way philosophy constructs and tests theories that it should not rest content with an established research program and a fixed consensus as long as there remain interesting theoretical problems to discuss. New ideas are generated, and old ones are improved, by constantly contesting the established consensus and using the discussion that emerges to refine popular options and reject those that can't stand the pressure. In fact, occasionally possibilities, which have already been shown to be unstable in philosophy, are later reproduced in the scientific discourse. In such cases it comes in handy that philosophy has already run through these theoretical possibilities and identified their respective weaknesses. An obvious example is Cartesian philosophy of mind, as thematized by Hacker \& Bennett (2003).

Where other disciplines test theories for their empirical implications, philosophy focuses on testing them for their qualities as theories. This means whether they involve things like: 1) dubious assumptions, 2) incoherence/ inconsistency, 3) vicious circularity, 4) conflations/ambiguities, 5) claims that have obvious counterexamples, 6)

\footnotetext{
${ }^{11}$ It must be noted that I am not denying that old theories can be resurrected again; the point is merely that such attempts typically have to answer a long list of standard objections.

${ }^{12}$ See Varela et al. (1991/93), Gallagher (2005), Gibbs (2005), and Gallagher \& Zahavi (2008). It should be noted that this author has another manuscript entitled “On How to make Philosophical Theories Useful for Scientific Purposes”, where he issues recommendations that are currently not implemented in this field of research.

${ }^{13}$ I say "stereotypical”, because I think that there is much more parallel development of theoretical edifices in empirical disciplines than this quick comparison allows for. But this is not the place to argue for this point, so I nevertheless retain the stereotypical picture for the purposes of the discussion.

${ }^{14}$ Initiatives like New Frameworks of Rationality (http://www.uni-giessen.de/cms/fbz/fb06/psychologie/abt/kognition-/spp1516) testify such a continued impact.
} 
good structural reasons for their having the particular shape that they do (so as to preclude the possibility of just modifying them with a rich supply of $a d$ hoc auxiliary hypotheses to avoid unpleasant challenges), 7) potential for further development in other domains to throw new light on the specific theoretical problems encountered there, 8) their compatibility with our general world-view and conception of ourselves, and 9) unacceptable consequences such as dualisms, ontological extravagancy, and the introduction of mysterious cognitive faculties.

The traditional armchair methodologies employing conceptual analysis, thought experiments, phenomenological analysis, and an extensive use of arguments informed by logic and common sense are just some of the ways philosophers typically go about doing this. But notice that we don't need to follow Klausen (2004) in holding that there are worldly facts, which are capable of functioning as truth-makers for philosophical claims in order to allow for an objective dimension of this discourse. For the discovery that a particular theory has one of the properties listed above, and the discovery that it fails in meeting requirements that have been established as general explanatory challenges for theories of its kind, contribute to the type of negative progress identified in section two.

That the present account enables us to talk about the objective discovery of properties of philosophical theories is an attractive feature, because it is easily seen how problematic Klausen's suggestion really is, once we begin applying it to the debates surrounding realism. At least two problems emerge. First, if the philosophical claims that the realist makes operate at a meta-level by concerning the philosophical interpretation of "all the familiar objects we interact with through perception and action", we apparently need to introduce "meta-level entities" as truth-makers for such philosophical claims. And if we in turn want to make claims at the meta-metalevel about how these latter philosophical claims are made true by "meta-level entities", we apparently need to introduce even more obscure entities etc. etc.. Similarly, the second problem emerges of what about when realists make philosophical claims about the world as a whole - where it is not an entity within the world, but actually the whole world, which allegedly makes such claims true-are they then precluded from ascending to the meta-level, because there are literally no more entities that can function as truth-makers than what made the original claims true?

Returning to our main theme: whereas the empirical sciences need to gather around large research programs to test theories systematically for their empirical implications, it is characteristic of the way philosophy tests its theories to disagree about too many things to have a comparable body of established truths. The hypothesis I offer for this state of affair is that an important part of the theoretical theory-testing in philosophy consists in constructing alternatives to popular theories to have something to systematically compare them with and to attack their basic assumptions. It thus lies in the very activity of philosophical theory-construction, and its corresponding theory-testing, to dissolve consensus and have an overproduction of alternatives in comparison to what would have been fruitful had the goal been to gather around unified research programs.

The structural reason given for this state of affairs is that testing theories in this manner requires a lot of alternatives and critical discussion to be effective-where the effectiveness consists in: 1 ) the capacity to identify strengths and weakness of the theories advanced, 2) the capacity to cover as much of the landscape of theoretical possibilities as possible, and 3) the capacity to come up with new ideas, which throw unexpected light on familiar theoretical problems.

It is in other words the ruthless competition that is the driving force of this enterprise. Its effect consists in forcing an ever increasing ingenuity in defending known options and an ever greater imagination in discovering new ones. Since more possibilities are probably kept alive simultaneously than in most other disciplines, it is only to be expected that we find less agreement here than there. Of course, more agreement could be produced, if some way of excluding a large number of these possibilities earlier in the process was found. But then we would also be in a worse position to overview the theoretical landscape, be less likely to make new discoveries from unexpected avenues, and have less pressure constantly to rethink the theories currently in favor.

By this I don't mean to suggest that the individual philosopher isn't out to close off possibilities and demonstrate the superiority of his own views. In fact, I think Dummett (2010) is probably right that the individual philosopher engaged in this substantive sort of theory-construction sees himself as aiming at the truth (although I find it notoriously hard to grasp in what sense there can be true philosophical claims). Rather the point is that the discipline as a whole has a tradition for being more tolerant of continued research into theoretical possibilities that haven't yet been refuted, but which I suspect that other, less-speculative disciplines would have dismissed as irrelevant more quickly. Christopher Gauker's long-standing attempt of exploring an alternative to the widely accepted "Lockean theory of language"-according to which communication is depicted as a sharing of propo- 
sitional thoughts in the mind of the speaker with the hearer (see Gauker, 2003)—is a nice example of this tendency. And indeed, publications such as Perlman (2000) seems to testify to such a tolerance, where the somewhat unusual path—which the author himself admits sounds "preposterous" and "perfectly mad" (xvii)—is explored of attempting to do without a notion of error and misrepresentation after the perceived failure of naturalistic accounts of representation and meaning has been disclosed.

I think it is fair to say that the hypothesis put forward here explains why one at most sees locally shared research programs in philosophy. It also explains why one of the major kinds of progress one finds in the history of philosophy is a graveyard of rejected possibilities, where the attempts to develop them into systematic accounts have failed in one of the ways mentioned. It is therefore the hope that this hypothesis can allow us to get a more a more realistic assessment of the actual merits of philosophy as a distinct, cognitive discipline, when one takes its history into consideration ${ }^{15}$.

I also promised to come up with a model for philosophical theory-construction, and it is to this task that I turn in section four, after having put more pressure on Hacker's views in section three.

\section{Explanatory Theories in Philosophy}

Hacker says: "It is true to say that philosophy does not explain phenomena as the sciences do" (Hacker, 2009b: p. 148). But if taken as a description of the philosophical practice-and not merely as an attempt to revise it in the image of Hacker's preferred style of thinking - then this cannot be quite right.

According to Smith (2002/5), "the problem" of philosophy of perception is the question, whether we can ever directly perceive the physical world. And there is no way of solving this problem, unless one explains how the possibility of us doing so is compatible with the phenomena of perceptual illusion and hallucination. Indeed, Smith takes great pain to come up with the right explanation of these particular phenomena; just as every other philosophical theory of perception I can think of. More recently, cognitive neuroscience has added blindsight, change blindness, inattentional blindness, visual agnosia, Anton's syndrome, and split-brain to the list of phenomena that need to be explained by such theories. There is no way a philosopher could have imagined the possibility of such strange phenomena from his or her armchair, and it is surely a good reason to reject a theory, if it turns out to be incompatible with their existence. For discovered actualities correct our modal intuitions by supplying us with existence proofs of possibilities that we may otherwise be inclined to exclude due to the acceptance of philosophical claims purporting to state conflicting necessities. Philosophers therefore need to pay close attention to the discovery of such phenomena and come up with a suitable explanation of them, if they want to continue maintain their own theories.

But in what sense do philosophers then provide explanations? Nozick (1981: p. 12) usefully suggests that understanding $x$ locates it in its possible connections with other possibilities, and that explaining $x$ locates it in its actual connection with other actualities (which means that explanation is a species of understanding that deals with actualized possibilities). As he points out, since philosophical problems often have the character of "How is x possible?" in the light of accepted claims, which are apparently incompatible with it, philosophical explanations typically take the form of resolving such incompabilities (8f). Applied to the example above, our general realistic world-view suggests that it is possible directly to perceive the physical world, and philosophers like Smith therefore attempt to explain how this can be so in the light of the actuality of phenomena like perceptual illusion and hallucination.

Moreover, when naturalistically inclined philosophers attempt to show that some entity (e.g. consciousness, meaning, normativity) is compatible with the ontology of the scientific image, then this may fruitfully be seen as a further species of this kind of "how-possible" explanation. "How-possible" explanations thus make up one important species of explanations in philosophy, but there may also be others.

\subsection{Making Theories about the Nature of $W$}

To be sure, Hacker also discusses puzzling phenomena such as those mentioned above in Hacker \& Bennett (2003). But the difference is that for him the purpose of this is to identify transgressions of the boundary of sense, according to our ordinary use of the concepts in question, to prevent us from producing nonsense. This contrasts with philosophers interested in making theories about what falls under $\mathrm{W}$, who merely use conceptual

\footnotetext{
${ }^{15}$ Yet another candidate for explaining the familiar observations we began with would be the midwife view. But it can at most provide part of the explanation for the reasons Hacker (2009b: pp. 131-133) gives.
} 
analysis as a tool among others and acknowledges that its results may be suspended by revisionary metaphysics, if the stakes are high enough ${ }^{16}$. For such philosophers are interested in the new and puzzling phenomena discovered for the purpose of making better theories.

Since Hacker's positive view on philosophy precludes philosophers from being interested in the nature of the things referred to by our concepts in this way, we here see how limited Hacker's interest in the nature of W really is: he is only interested in the nature of $\mathrm{W}$, insofar as it is reflected in our use of the concept W. Hence, it seems that Hacker's own position is a good example of what Williamson accused the linguistic turn of - in spite of Hacker's own persistent insistences to the contrary (cf. section one).

An example of the contrasting kind of philosophy is this: there is a growing debate about, whether the seemingly rich detailed character of our visual awareness rests on "a grand illusion" created by the brain ${ }^{17}$. Part of the reason is that change blindness and inattentional blindness suggests that we are not attending to great parts of what is going on in our immediate visual vicinity, and part of the reason is that empirical discoveries about the anatomy of our eyes have convinced scientists that we are highly selective in the information uptake from our environment. Now for someone like Dretske, who has defended a theory of perception ever since Seeing and Knowing (1969), which holds that we are overloaded with visual information in perception that by far exceeds our cognitive digestion, such findings present a central explanatory challenge. And it is one which Dretske (2004, $2006,2007)$ confronts. This style of philosophy is not merely concerned with misuse of our concept of W; it attempts to explain things and construct theories about their nature.

Discovering such phenomena may also force a revision of existing vocabulary. For why assume, without further ado, that our ordinary concept of seeing is geared to handle such rare cases as blindsight, which have only recently been discovered? What exactly is it about our past record of using the concept to describe the behavior of ordinary people that is supposed to uniquely determine how to describe that of patients with exotic brain lesions? Taken literally, "blind-sight” is a paradoxical name, as Hacker \& Bennett (2003: p. 394) note. Perhaps the reason is that it goes against our ordinary conception that patients can achieve a $90 \%$ accuracy of, say, guessing the rotation of objects in a region of their visual field, where they are supposed to be clinically blind. Furthermore, the fact that there is a large discussion among competent language users about how best to describe the case with our existing concepts should make us pause. For maybe it is a borderline case, where we have to find out how best to integrate the description we converge on in this novel case with how we would describe more paradigmatic cases. It is at least not obvious that such exotic cases are compatible with being conservative about our linguistic practice.

Hacker \& Bennett (2003: p. 396) assume that there are perfectly determinate rules governing language use, and they think that one can avoid the paradoxical descriptions of blindsight by paying close attention to such rules. Accordingly, blindsight should be described as the dissociation of two behavioral criteria, which normally define correct applications of the concept of seeing, where the consequence is that this concept is inapplicable under such special circumstances. Hacker and Bennett thus advise us not to call it "blindsight", because it is a paradoxical name, and that we refrain from either saying, or not saying, that the patients see, because this doesn't fit with how the concept of seeing has been applied before we encountered these rare cases.

However, these patients still reliably register visual stimuli from the environment in a way that one couldn't, if one were completely blind. So it is left in obscurity what exactly we should call it then-whatever it is that they are doing.

The neuroscientific problem the phenomenon poses is this:

How the brain continues to process visual information in the absence of both acknowledged visual perception and the primary visual cortex that retinotopically corresponds to the relevant part of the visual field, while enabling the subject voluntarily and correctly to respond to the unseen stimuli (Cowey, 2010: p. 3).

Some of the philosophical problems it poses are: 1) how to gradate awareness (Nozick, 2001: pp. 174-190), 2) what are we to make of the notion of perception without awareness suggested by the psychological literature, and which criteria of conscious awareness can be given (Dretske, 2006), 3) can blindsight be taken to support higher order theories of consciousness (Gallagher \& Zahavi, 2008: pp. 57-61), 4) does blindsight help undermine the philosophical thesis that conscious propositional thought is necessary for objective perceptual repre-

\footnotetext{
${ }^{16}$ For example, Jackson (1998: pp. 44-45) argues that this might be the most reasonable thing to do in regard to our ordinary concepts of freedom and personal identity.

${ }^{17}$ See Nöe (2002).
} 
sentations (Burge, 2010: pp. 188-189), and 5) does blindsight force us to revise or reject existing philosophical theories of perception or consciousness in general.

It is not obvious how following the linguistic advices of Bennett and Hacker of what not to call the phenomenon helps us dealing with these substantial issues.

\subsection{Sense-Determining Rules and Hacker's Own Theoretical Commitments}

In his response to Hacker, Dennett (2007) accuses ordinary philosophy of language of making one big bluff, when it proclaims to know these semantic rules.

In agreement, I think that a more plausible image of the norms determining the content of our empirical concepts is the one found in Brandom's Hegel interpretation ${ }^{18}$, which uses "judge-made laws" in the common law tradition as its model for the development of the determinacy of empirical concepts. According to this model, it isn't assumed that it is completely determined in advance how to apply such concepts in every novel case. Rather through our application of empirical concepts in novel cases we contribute to giving them a determinate content. But this doesn't mean that we are completely unconstrained by past correct applications, because by applying a familiar concept in a novel case we adopt the task-responsibility of being able to rationally integrate our present use with what was correct in past uses. The use of precedents in common law can be used as a model for how this occurs. Retrospectively, we reconstruct past uses as if they were governed by completely determined rules, when discharging the task-responsibility of rationally integrating the present decision with past ones. But seen from a prospective perspective, there isn't actually a set of static rules, which everybody knows.

I submit that this latter account fits better with our experience of applying familiar concepts in unfamiliar situations than the image of us attempting to figure out what is correct according to a stack of static rules, which are only modified by the introduction of new definitions ${ }^{19}$. For as Millikan (2005: p. v) points out, there is little evidence that we were taught "the rules of language" in the same way we teach our children, say, the rules of chess $^{20}$.

If one adopts the account suggested, it is only to be expected that we have to extend our concepts, when we encounter new and puzzling phenomena like blindsight in much the same way as, say, the internet has introduced a whole new domain of legal disputes.

But perhaps I am wrong about the superiority of this view, and perhaps Hacker is right in attributing semantic rules a fundamental role. But if so, then this is a dispute among two competing philosophical theories, which should be settled in the way philosophers usually settle these kinds of things; by comparing the theories in question for their respective weaknesses and strengths.

I therefore think that Churchland (2005: p. 475f) is right in pointing out that Hacker is advocating a particular theory of language that can be challenged. But tellingly Hacker has not responded to this point ${ }^{21}$, because his official view is that philosophy is not a cognitive discipline in the business of theory-construction, so he is not supposed to advance any theories on his own.

Accordingly, his adoption of a commitment to the Aristotelian theory of mind over against a Cartesian theory of mind (and all its descendants) is also disguised as merely a matter of laying out the rules governing ordinary language use-instead of being presented as a matter of adopting a commitment to a superior philosophical theory. Furthermore, his critique of substance-dualism is thus that it is incoherent and senseless.

But even if he is right that the Cartesian theory of mind doesn't cohere with the way we use our concepts, it could just be put forward as a piece of revisionary metaphysics for the purpose of solving deep theoretical problems, if indeed it managed to solve any. But, of course, here lies the real difficulty with this theory. It is not that it is literally senseless, but rather that it is a bad theory, because it introduces more problems than it solves due to the fact that it distinguishes between two items, which belong together, in a way that makes it unintelligible exactly how they are supposed to be related ${ }^{22}$.

But as I have said, Hacker doesn't admit that he adopts a commitment to a range of particular philosophical theories, because he doesn't see it to lie within the province of philosophy to do so. The effect is that he thereby

\footnotetext{
${ }^{18}$ See Brandom (2006: pp. 458-464, 2009: chap. 3).

${ }^{19}$ See Hacker \& Bennett (2003: pp. 385-386).

${ }^{20}$ See also Pinker (2007: pp. 28-29).

${ }^{21}$ See Hacker \& Bennett (2007).

${ }^{22}$ Cf. Brandom (1994/98: p. 615).
} 
creates the illusion that he is capable of ruling out all the philosophical theories he disagrees with under the guise of his stated view that his own theories are merely putting forward conceptual truths, which one cannot dispute without producing nonsense.

\section{Philosophical Theory-Construction}

It is about time that I say something about what philosophical theory-construction consists in. The best suggestion I have is that it consists in combining a range of theoretical commitments into a systematic account, where some of them have clear empirical implications and others concern more traditional normative issues in philosophy having to do with epistemology, semantics, and ontology. Here are two examples of what I mean.

When constructing a theory of perception, one must arguably make sure that it is compatible with: 1) relevant empirical findings (e.g. from patients with brain lesions, which challenge our ordinary understanding of various perceptual phenomena), 2) a plausible account of animal perception, 3) an ontologically parsimonious account of perceptual illusions and hallucinations, which doesn't introduce epistemological intermediaries and yet takes the causal dimension of perception seriously, 4) perception being a standard source of justification and that one can account for this without falling into the Myth of the Given, and 5) central distinctions drawn on the basis of conceptual analysis, phenomenological investigations from the first person perspective, and of an analysis of attributions of perceptual knowledge.

The big challenge is to integrate into a systematic account the theoretical commitments one adopts in meeting all of these criteria of adequacy, because they may point in different directions. For instance, accommodating 2) may lead one to adopt a commitment to the claim that perceptions have a non-conceptual content, whereas accommodating 4) may lead one to adopt a commitment to the claim that they have a conceptual content. Moreover as the example shows, some of these commitments will be sensitive to recent empirical findings, whereas others concern more traditional issues in philosophy having to do with ontology, epistemology, and semantics.

Smith (2002/5) and Coates (2007) provide good examples of philosophers attempting to satisfy most of the criteria of adequacy listed, and they thus nicely illustrate how I think philosophical theory-construction should proceed.

The second example is taken from philosophy of language. When constructing a philosophical theory of meaning, one must arguably make sure that it is compatible with: 1) ontological parsimony (this means no postulation of meaning entities, semantic facts etc., unless there is no alternative), 2) a robust account of semantic objectivity (the fact that there is a difference between being correct and merely seeming to be correct about how to apply assertive content, which allows even the whole linguistic community to err in particular cases), 3) an account of language acquisition (the theory shouldn't make language acquisition too demanding, and it needs to be compatible with findings in development psychology), 4) an account of the understanding involved in grasping the meaning of a sentence (and, on pain of regress, the most basic sort of understanding needs to involve basic know-how abilities), and 5) an account of the compositionality of language (because otherwise we have no way of explaining how speakers with finite abilities and vocabularies can understand an infinite amount of novel sentences).

Again in meeting all of these criteria of adequacy, one will have to adopt some commitments, which have direct empirical implications ${ }^{23}$, and others that have to do with more traditional concerns in philosophy.

Philosophers are not just concerned with explaining particular empirical phenomena such as the productivity of language or linguistic competence. But they also tend to locate their theories in a larger theoretical context to construct a complete view of the world and our place in it. This is why they investigate which epistemological, semantic, and ontological consequences theories have, and why they are typically interested in such issues as how our ordinary self-conception fits with the image of the world, and our place within it, which science

\footnotetext{
${ }^{23} \mathrm{An}$ example: if Garfield et al. (2001) are right that the acquisition of a theory of mind already presupposes language acquisition, and the social understanding acquired through conversation and interaction with others, then this might throw new light on (4). The reason is that semantic realism would then appear to be committed to treating children as capable of grasping the possibility of truth-conditions being satisfied undetectably before they are able to understand the possibility of there being varying doxastic perspectives on the world (which they normally learn when 3 - 5 years old). Hence, it should be possible to test the linguistic skills of children, who haven't acquired a theory of mind in order to find out, whether they are best described as, say, involving a grasp of truth-conditions realistically conceived or as merely involving an understanding of what it is to give and ask for reasons and practically mastering the inferential roles of the sentences they use. (However, in doing so it should be noted that Brandom's account also seems to require that they would be able to keep score on claims across differences in doxastic perspectives, which we have reasons to expect that they can't as the scenario has been described.)
} 
presents us with. And since this supply of knowledge is itself in dynamic change, so must the philosophy be, which undertakes to integrate these two types of images into a complete framework ${ }^{24}$. In this process many different possibilities need to be kept alive at the same time in order for philosophers to be able to accommodate the changing demands on their theories.

This suggests that the correct view to take is that some aspects of philosophical theories can be tested empirically, while acknowledging that there are others, which can only be scrutinized by using the skills of theoretical theory-testing, which philosophers have specialized in (cf. section two). Accordingly, a sharp a priori/a posteriori demarcation between the concerns of philosophy and those of empirical sciences is to be rejected for the following reasons: 1) it does more harm than good, if used by philosophers as an excuse to ignore significant empirical findings, 2) the nature of philosophical theory-construction on the model I have given doesn't warrant such a sharp distinction, because philosophers need to combine commitments that fall on both sides of it, and 3) surprising phenomena such as those encountered in neuropathology correct our modal intuitions by teaching us something about what is possible (and by implication: about what cannot be necessary), which philosophers would have no way of discovering for themselves from their armchairs ${ }^{25}$. Yet the significance of the strange phenomena uncovered is obvious for the kind of philosophical theories described above. This suggests that we should treat our ability to think about what is possible as more like a skill that we can train by what we learn about the world, and in this context study of various brain damages provides great education ${ }^{26}$.

Hacker (2009b) writes that: "No philosophical question can be answered by scientific enquiry, and no scientific discovery can be made by philosophical investigation”. So I find it fitting to end this paper with a quote directed against the first conjunct and then to continue my work on a further paper, which targets the second:

This [the issue of how much prior representational structure is needed to account for dead reckoning, NSO] is an echo of the debate between philosophical nativists, like Kant and Leibnitz, and philosophical empiricists, like Locke, Hume, and Berkeley. In our terms, Kant can be understood to have argued that a certain amount of representational structure was a precondition for having any experience whatsoever. Therefore, that representational structure could not derive from experience because experience itself was made possible only by virtue of the prior existence of that representational structure. Today, thanks to the power of modern computers, we are in a position to adopt a quasi-experimental approach to this ancient question. Because the behavioral evidence for dead reckoning is strong, and because the computation that must somehow be accomplished is so clear, we think this is an excellent area in which to explore the extent to which currently assumed rewiring rules and some to-be-specified assumptions about the structure of experience could produce the representational structure necessary for a neural network to compute its position function from its velocity function—online in real time (Gallistel \& King, 2010: p. 253) ${ }^{27}$.

\section{Acknowledgements}

Throughout the years, I have presented this material to many in verbal form, and I would like to thank them all for their interesting comments. Recently, I had two rewarding conversations with Edouard Machery about these issues. Moreover, I would like to thank Jens Chr. Haar for commenting on an early draft some four years ago.

\section{References}

Braddon-Mitchell, D., \& Nola, R. (Eds.) (2009). Conceptual Analysis and Philosophical Naturalism. Cambridge, MA: The MIT Press.

Brandom, R. (1994/98). Making It Explicit. Cambridge, MA: Harvard University Press.

Brandom, R. (2001). Modality, Normativity, and Intentionality. Philosophy and Phenomenological Research, 63, 587-609. http://dx.doi.org/10.1111/j.1933-1592.2001.tb00127.x

Brandom, R. (2006). Semantik ohne Wahrheit. Deutsche Zeitschrift für Philosophie, 54, 449-466.

\footnotetext{
${ }^{24}$ As the reader will notice, I am greatly inspired by the writings of Sellars at this point.

${ }^{25}$ Another interesting example is Aaron O'Connell's 2011-announcement in ted talks of the construction of a macro-sized quantum object both vibrating and not vibrating at the same time (see also Cho, 2010).

${ }^{26}$ Williamson (2007: p. 165ff) also rejects a sharp demarcation between a priori/a posteriori and it seems that the epistemology of modal and counterfactual knowledge he offers in chap. 5 would support the reason I offer in (c).

${ }^{27}$ Incidentally, Pinker (2000: pp. 89-90) suggests that the English past tense can be used as a similar testing ground for the same philosophical dispute.
} 
Brandom, R. (2009). Reason in Philosophy. Cambridge, MA: The Belknap Press of Harvard University Press.

Burge, T. (2010). Origins of Objectivity. Oxford: Clarendon Press.

Cho, A. (2010). The First Quantum Machine. Science, 330, 1604. http://dx.doi.org/10.1126/science.330.6011.1604

Chomsky, N. (2000). New Horizons in the Study of Language and Mind. Cambridge: Cambridge University Press. http://dx.doi.org/10.1017/CBO9780511811937

Churchland, P. M. (2005). Cleansing Science. Inquiry, 48, 464-477.

http://dx.doi.org/10.1080/00201740500242001

Coates, P. (2007). The Metaphysics of Perception. New York: Routledge.

Cowey, A. (2010). The Blindsight Saga. Experimental Brain Research, 200, 3-24. http://dx.doi.org/10.1007/s00221-009-1914-2

Davidson, D. (1996). The Folly of Trying to Define Truth. The Journal of Philosophy, 93, 263-278. http://dx.doi.org/10.2307/2941075

Dennett, D. (2007). Philosophy as Naive Antropology: Comment on Bennett and Hacker. In D. Robinson (Ed.), Neuroscience and Philosophy: Brain, Mind \& Language (pp. 73-95). New York: Columbia University Press.

Dretske, F. (1969). Seeing and Knowing. London: The University of Chicago Press.

Dretske, F. (2004). Change Blindness. Philosophical Studies, 120, 1-18. http://dx.doi.org/10.1023/B:PHIL.0000033749.19147.88

Dretske, F. (2006). Perception without Awareness. In T. S. Gendler, \& J. Hawthorne (Eds.), Perceptual Experience (pp. 147-180). New York: Oxford University Press. http://dx.doi.org/10.1093/acprof:oso/9780199289769.003.0005

Dretske, F. (2007). What Change Blindness Teaches about Consciousness. Philosophical Perspectives, 21, 215-230. http://dx.doi.org/10.1111/j.1520-8583.2007.00126.x

Dummett, M. (2010). The Nature and Future of Philosophy. New York: Columbia University Press.

Gallagher, S., \& Zahavi, D. (2008). The Phenomenological Mind. New York: Routledge.

Gallagher, S. (2005). How the Body Shapes the Mind. Oxford: Clarendon Press. http://dx.doi.org/10.1093/0199271941.001.0001

Gallistel, C. R., \& King, A. P. (2010). Memory and the Computational Brain. Why Cognitive Science Will Transform Neuroscience. Singapore City: Blackwell Publishing.

Garfield, J. L., Peterson, C. C., \& Perry, T. (2001). Social Cognition, Language Acquisition and the Development of the Theory of Mind. Mind \& Language, 16, 494-541. http://dx.doi.org/10.1111/1468-0017.00180

Gauker, C. (2003). Words without Meaning. Cambridge, MA: The MIT Press.

Gibbs, R. W. (2005). Embodiment and Cognitive Science. New York: Cambridge University Press. http://dx.doi.org/10.1017/CBO9780511805844

Glock, H. J. (2008). What Is Analytic Philosophy? New York: Cambridge University Press. http://dx.doi.org/10.1017/CBO9780511841125

Gutting, G. (2009). What Philosophers Know. Case Studies in Recent Analytic Philosophy. New York: Cambridge University Press. http://dx.doi.org/10.1017/CBO9780511841156

Hacker, P. M. S., \& Bennett, M. R. (2003). Philosophical Foundations of Neuroscience. Oxford: Blackwell Publishing.

Hacker, P. M. S., \& Bennett, M. R. (2007). The Conceptual Presuppositions of Cognitive Neuroscience. A Reply to Critics. In D. Robinson (Ed.), Neuroscience \& Philosophy: Brain, Mind, \& Language (pp. 127-62). New York: Columbia University Press.

Hacker, P. M. S. (2006). Analytical Philosophy: Beyond the Linguistic Turn and Back Again. In M. Beaney (Ed.), The Analytic Turn: Analysis in Early Analytic Philosophy and Phenomenology (pp. 125-141). New York: Routledge.

Hacker, P. M. S. (2007). Human Nature: The Categorical Framework. Oxford: Blackwell Publishing.

Hacker, P. M. S. (2009a). A Philosopher of Philosophy. Philosophical Quarterly, 59, 337-348. http://dx.doi.org/10.1111/j.1467-9213.2008.587.x

Hacker, P. M. S. (2009b). Philosophy: A Contribution, Not to Human Knowledge, but to Human Understanding. In A. O’Hear (Ed.), Conceptions of Philosophy (pp. 129-53). New York: Cambridge University Press.

Jackson, F. (1998). From Metaphysics to Ethics: A Defense of Conceptual Analysis. Oxford: Clarendon Press.

Klausen, H. S. (2004). Reality Lost and Found. An Essay on the Realism-Antirealism Controversy. Odense: University Press of Southern Denmark.

Millikan, R. (2005). Language: A Biological Model. Oxford: Clarendon Press. 
Noë, A. (Ed.) (2002). Is the Visual World a Grand Illusion? Journal of Consciousness Studies, 9, 1-12.

Nozick, R. (1981). Philosophical Explanations. Cambridge, MA: The Belknap Press of Harvard University Press.

Nozick, R. (2001). Invariances. The Structures of the Objective World. Cambridge, MA: The Belknap Press of Harvard University Press.

Peacocke, C. (2010). Truly Understood. Oxford: Oxford University Press.

Perlman, M. (2000). Conceptual Flux. Mental Representation, Misrepresentation, and Concept Change. Dordrecht: Kluwer Academic Publishers. http://dx.doi.org/10.1007/978-94-015-9462-2

Pinker, S. (2000). Words and Rules: The Ingredients of Language. New York: Perennial.

Pinker, S. (2007). The Language Instinct: How the Mind Creates Language. New York: Harper Perennial Modern Classics.

Smith, A. D. (2002/5). The Problem of Perception. Delhi: Motilal Banarsidass Publishers.

Spohn, W. (2012). The Laws of Belief: Ranking Theory and Its Philosophical Applications. Oxford: Oxford University Press. http://dx.doi.org/10.1093/acprof:oso/9780199697502.001.0001

Varela, F. J., Thompson, E., \& Rosch, E. (1991/93). The Embodied Mind. Cognitive Science and Human Experience. Cambridge, MA: The MIT Press.

Williamson, T. (2007). The Philosophy of Philosophy. Oxford: Blackwell Publishing. http://dx.doi.org/10.1002/9780470696675 
Scientific Research Publishing (SCIRP) is one of the largest Open Access journal publishers. It is currently publishing more than 200 open access, online, peer-reviewed journals covering a wide range of academic disciplines. SCIRP serves the worldwide academic communities and contributes to the progress and application of science with its publication.

Other selected journals from SCIRP are listed as below. Submit your manuscript to us via either submit@scirp.org or Online Submission Portal.
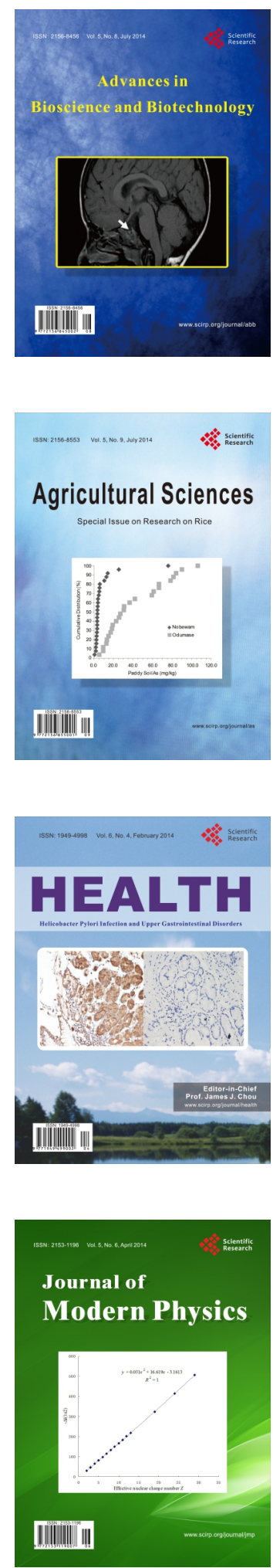
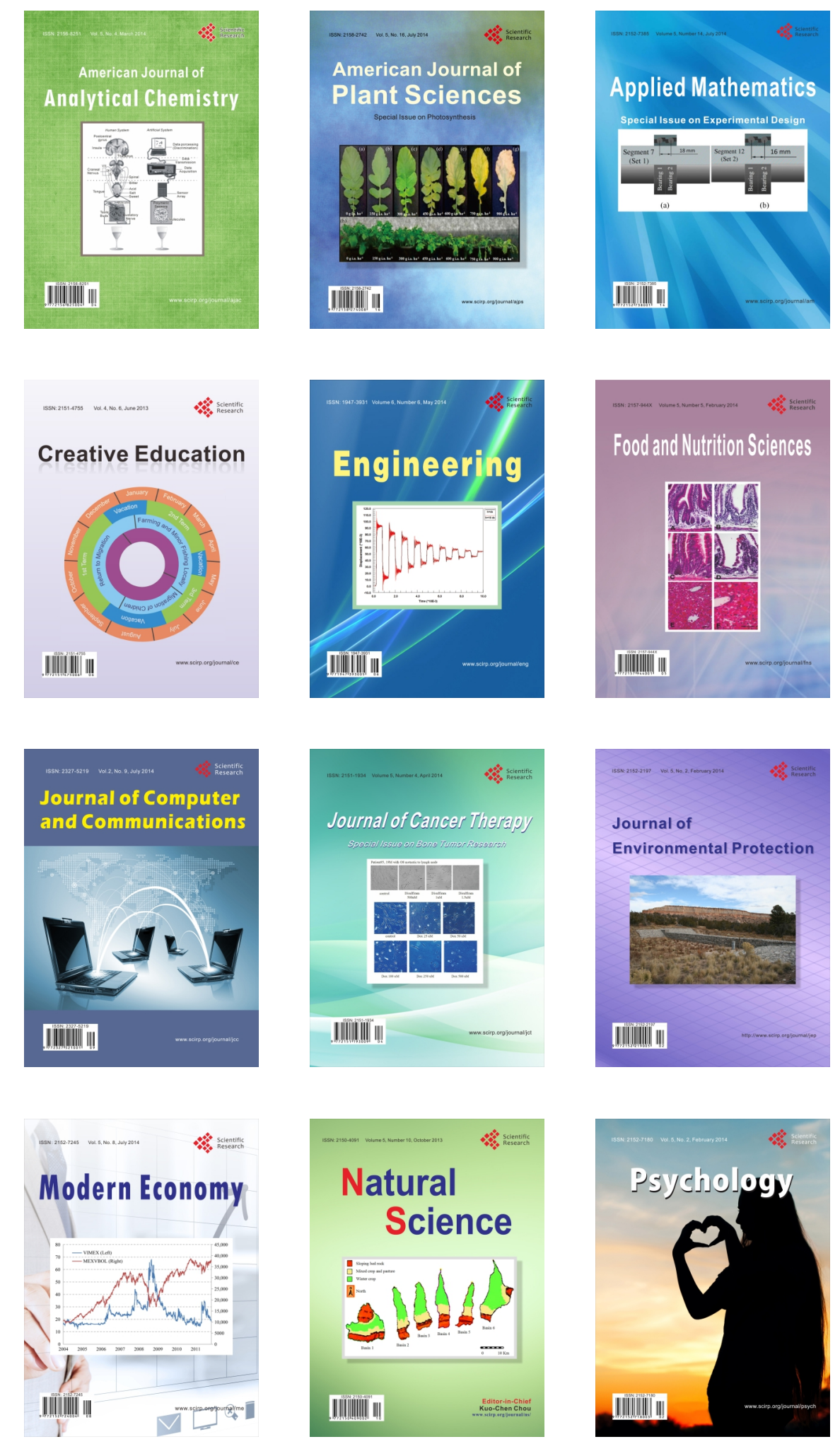